\title{
Dispositivos móveis na educação: ensinando e aprendendo em diferentes contextos.
}

\author{
Karla Angélica Silva do Nascimento ${ }^{1}$, José Aires de Castro Filho \\ ${ }^{1}$ Universidade Federal do Ceará (UFC) \\ Caixa Postal 60020-110 - Fortaleza - CE - Brasil \\ ${ }^{2}$ Instituto UFC Virtual - Universidade Federal do Ceará (UFC) \\ Caixa Postal 60440-554 - Fortaleza - CE - Brasil \\ $\{$ karla, aires\}@virtual.ufc.br
}

\begin{abstract}
This article describes part of a research on mobile learning from the teachers perception towards the development of an educational project in the discipline of Sciences of the 7th year of elementary school in a public school, supported by mobile devices with activities that go beyond the room of class. Based on action research methods, we analyze the use of two applications: Whatsapp and online form Drive in order to bring the curriculum content on the plant and animal kingdoms, relating to a real community problem to the environment of the school. The results show that integrating mobile technologies in collaborative practices in the educational context implies thinking about the benefits and the possibility of using them to support the teaching.
\end{abstract}

Resumo. Este artigo descreve parte de uma pesquisa sobre mobile learning, a partir da percepção docente em relação ao desenvolvimento de um projeto pedagógico na disciplina de Ciências do $7^{\circ}$ ano do Ensino Fundamental de uma escola pública, apoiado por dispositivos móveis com atividades que vão além da sala de aula. Com base nos métodos de pesquisaação, analisamos a utilização de dois aplicativos: Whatsapp e formulário online do Google Drive, a fim de aproximar os conteúdos curriculares sobre os reinos vegetais e animais, relacionando a um problema real da comunidade ao entorno da escola. Os resultados mostram que integrar as tecnologias móveis em práticas colaborativas no contexto educativo implica pensar nos benefícios e na possibilidade de utilizá-los para apoiar o trabalho docente.

\section{Introdução}

Os dispositivos móveis proporcionam, cada vez mais, diversos recursos multimídia que podem favorecer a educação quando se há mediação docente e objetivo pedagógico claro. Apesar disso, as abordagens pedagógicas destes dispositivos no Ensino Fundamental têm sido pouco exploradas. Assim, existe uma necessidade de analisar a aprendizagem móvel (mobile learning), a partir da percepção docente em diferentes contextos.

Segundo Nascimento e Castro Filho (2015), a maior parte dos artigos sobre mobile learning, em revistas científicas, está localizada em países estrangeiros. Além disso, 3/4 destes estudos estão relacionados ao Ensino Superior, Educação a Distância e Educação Profissional. Os autores concluíram que há carência de pesquisas que abordem a aprendizagem móvel e seus aplicativos no Ensino Fundamental.

Estudar sobre aprendizagem móvel, tendo como base a teoria sociocultural, ajuda os professores a refletirem sobre suas atividades de ensino, oferecendo uma concepção crítica sobre a utilização de dispositivos e aplicativos móveis que favoreçam a interação, colaboração na prática docente em diferentes contextos educativos. A 
V Congresso Brasileiro de Informática na Educação (CBIE 2016)

Anais do XXVII Simpósio Brasileiro de Informática na Educação (SBIE 2016)

estrutura deste estudo oferece uma avaliação sobre m-learning que coloca em primeiro plano as metodologias pedagógicas ao utilizar tablets e smartphones nas aulas de Ciências, integradas ao plano curricular e a um projeto voltado para ações sustentáveis.

Dessa forma, investigamos uma das atividades desenvolvidas em uma pesquisa sobre aprendizagem móvel, a partir de uma perspectiva sociocultural. Esta abordagem teórica sugere que o aprendizado é modificado pelos recursos utilizados no processo de ensino e aprendizagem, ao mesmo tempo compreende que estes também são modificados para favorecer tal ação.

\section{O que é Mobile Learning (m-learning)?}

Os estudiosos (LIU et al., 2014; MEHDIPOUR; ZEREHKAFI, 2013; SHARPLES et al., 2010, 2013; TRAXLER, 2010; ROSCHELLE et al., 2010; KUKULSKA-HULME, 2010) definem m-learning de várias maneiras, mas todos consideram que, devido aos avanços tecnológicos, é o processo de aprendizagem apoiado por dispositivos móveis.

$\mathrm{Na}$ opinião de Sharples et al. (2010), a definição deve focar na oferta de educação e formação em dispositivos como tablets e smartphones. Para os autores, a educação entra na chamada terceira onda tecnológica que descortina a comunicação sem fio caracterizada pelo uso de dispositivos móveis amigáveis, baratos, fáceis de usar e pessoais transportados a todo lugar.

Em contrapartida, Kukulska-Hulme (2010) não seleciona os tipos de dispositivos móveis mais adequados. Ao invés disso, o autor destaca três razões que sustentam o uso da tecnologia móvel na educação: a melhoria do acesso, a exploração do potencial de mudanças no ensino e na aprendizagem, e o alinhamento com os objetivos educacionais. A perspectiva é que os alunos valorizem seu próprio processo de aprendizagem, os professores se interessem em buscar estratégias de apresentar os assuntos das aulas de uma maneira diferente da que veriam sem o uso de dispositivos móveis. Além disso, há esperança dessas tecnologias reduzirem barreiras culturais e de comunicação.

Para Traxler (2010), o ensino tradicional pode ser caracterizado por duas constantes ou limites: tempo e espaço, uma vez que os ambientes físicos e os horários de aulas são relativamente imutáveis. Diante disto, o autor revela que $m$-learning tem o potencial de transcender essas restrições espaciais e temporais, superando a necessidade de amarrar atividades específicas para determinados lugares ou tempos particulares.

Vemos que as tecnologias móveis estão cada vez mais mudando a natureza do conhecimento e do discurso na sociedade, principalmente nos países desenvolvidos ou em desenvolvimento. Isto altera tanto a natureza da aprendizagem formal e não-formal como as estratégias de aprendizagem ao longo da vida.

Essas tecnologias podem ser usadas em diversas áreas temáticas e os alunos podem construir e aplicar conhecimentos e habilidades de forma individual ou colaborativamente em diferentes contextos. Conforme Vygotsky (2007), o conhecimento se faz pela mediação feita por outros sujeitos ou por meio de objetos do mundo que rodeia o indivíduo. O professor é um mediador desse processo, por isso se faz necessário analisar suas percepções sobre essas práticas no âmbito da aprendizagem móvel. 
V Congresso Brasileiro de Informática na Educação (CBIE 2016)

Anais do XXVII Simpósio Brasileiro de Informática na Educação (SBIE 2016)

\section{Procedimentos Metodológicos}

Neste trabalho observamos práticas colaborativas com apoio de dispositivos móveis mediadas por uma professora do Ensino de Ciências ( $\operatorname{Prof}^{a} \mathrm{~L}$ ) e desenvolvidas pela sua turma de $7^{\circ}$ ano, turno manhã, do Ensino Fundamental com 25 alunos, estabelecendo uma concepção específica de pesquisa-ação realizada no segundo semestre de $2015 \mathrm{em}$ uma escola pública municipal cearense. A pesquisa-ação tem como perspectiva inserir o professor no processo de investigação. Ele deixa de ser objeto e passa a ser sujeito e colaborador em todo o percurso da pesquisa (THIOLLENT, 1985).

No que se refere aos instrumentos de coleta, foram utilizadas entrevistas, observações das aulas e diário de campo. Os procedimentos éticos adotados nesta investigação se valeram da aprovação do seu projeto no Comitê de Ética em Pesquisa (CEP), como também a elaboração dos seus termos normativos, consentidos pela professora, gestora da escola e pais dos alunos.

Com base na compreensão da Prof. L de que as tecnologias poderiam melhorar sua relação com os alunos, pois se preocupava com a evasão que crescia consideravelmente, ela, com ajuda da pesquisadora, almejou colocar em prática um projeto que abordasse conteúdos trabalhados em sala de aula, como também fizesse uso inteligente das tecnologias móveis no cotidiano pedagógico. Assim, a partir do objetivo principal da investigação, professora e pesquisadora estiveram presentes em todos os momentos. Esse processo aconteceu de modo colaborativo em que a Prof ${ }^{\mathrm{a}}$ L dividiu suas angustias, seus valores, seus sonhos, suas ideias, visando mudar as circunstâncias em que se encontrava, como também a si própria.

O Projeto "Reflorestamento e Tecnologia Móvel: cuidando da arborização do bosque" foi desenvolvido com base no cuidado e preservação do meio ambiente, nas ações sustentáveis do bosque localizado ao lado da escola, na utilização de dispositivos móveis para favorecer o ensino e a produção coletiva dos alunos e no protagonismo juvenil que corrobora para a formação de pessoas mais autônomas e comprometidas socialmente. Os dados gerados da pesquisa foram sintetizados para apresentação dos resultados.

\section{Resultados}

A vantagem de a qualquer hora e em qualquer lugar, usando dispositivos móveis, favoreceu o desenvolvimento das práticas colaborativas. No Projeto, a Prof ${ }^{\mathrm{a}} \mathrm{L}$ e sua turma utilizaram vários aplicativos, no entanto, trataremos do aplicativo Whatsapp e do formulário online do Google Drive, a fim de aproximar os conteúdos curriculares sobre os reinos vegetais e animais propostos na sua disciplina, relacionando a uma situação real, ações sustentáveis no bosque ao lado da escola, solicitando, aos alunos, levantamento e comparação das espécies de plantas e animais. Segundo Silva et al. (2013) as ferramentas do Google Drive promovem projetos colaborativos, dinamiza o trabalho pedagógico e gera aprendizagem.

Enquanto a Prof ${ }^{a} \mathrm{~L}$ explicava a necessidade de registrar por meio de fotos as plantas do bosque, de classificar e de pesquisar seus nomes científicos, os alunos compartilhavam fotografias e informações através de Bluetooth ou anexavam no grupo pelo Whatsapp, criado e intitulado pelos alunos de "Restaura (nome da cidade)". 
V Congresso Brasileiro de Informática na Educação (CBIE 2016)

Anais do XXVII Simpósio Brasileiro de Informática na Educação (SBIE 2016)

Este compartilhamento de informações foi tão naturalmente interiorizado pela Prof $^{a}$ L que ela nem se deu conta que estava usando de maneira diferente daquilo que fazia antes desta prática, por exemplo: antes ela imprimia ou digitalizava as imagens, fotocopiava e distribuía aos alunos. Algumas participações dos alunos e da professora foram identificadas pelos quatro primeiros números do celular e retratadas a seguir:

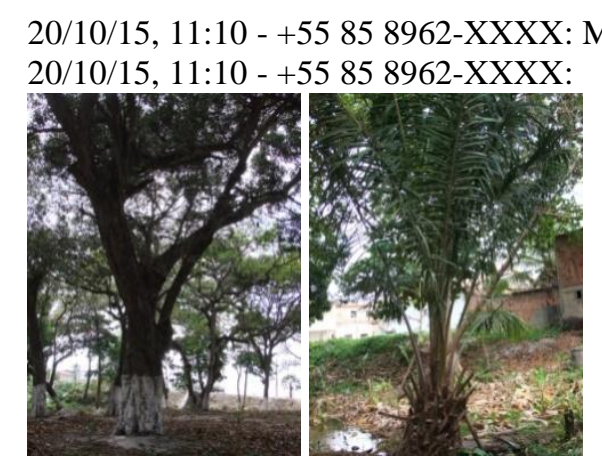

20/10/15, 11:12 - +55 85 8557-XXXX: Eu testei aki com a tia e tb dá certo com o cartão eh só tirar foto e depois tira o cartão do celular e bota no netbook

20/10/15, 11:12 - +55 85 8962-XXXX: vamo combinar de tira mais hj de tarde e depois fazer o mapa

20/10/15, 11:13 - +55 85 8885-XXXX: Tb vou

26/10/15, 11:30 - +55 85 8658-XXXX: Ei glr! Tá combinado hj a entrevista com a dona mundoca, viu naum eh pra esqcer

26/10/15, 11:30 - +55 85 8782-XXXX: Ok

26/10/15, 11:30-+55 85 8797-XXXX: Blz

26/10/15, 11:30 - +55 85 9731-XXXX: Certo

03/11/15, 14:42 - +55 85 8658-XXXX: tia a gente tá aki cadê a senhora?

03/11/15, 14:42 - $\operatorname{Prof}^{a}$.L: Pessoal, estou aqui no laboratório, vamos nos reunir aqui, chamem todos pra cá!

Observamos nesse trecho que o aplicativo foi usado depois da aula e que em alguns momentos ele servia para compartilhar dados gerados das suas pesquisas no bosque, como também para organizar encontros com o intuito de desenvolver melhor as atividades, por exemplo: combinaram de se encontrar no contraturno de aula para entrevistar uma antiga moradora que conhecia as espécies nativas de plantas.

Nas aulas de campo, a $\operatorname{Prof}^{\mathrm{a}} \mathrm{L}$ recomendava a turma que fotografasse as espécies de vegetais e animais, pois em outro momento usaria tais registros para analisálos, discuti-los e compará-los, conforme o conteúdo sobre o reino vegetal. Nas aulas seguintes, os alunos apresentavam suas fotos acompanhadas de informações que haviam pesquisado na Internet. Isso também aconteceu ao comparar os tipos e quantidade de plantas existentes no bosque. Na maioria das vezes, os dados eram armazenados nos tablets e depois compartilhados aos demais.

Como nem todos tinham smartphones, a Prof ${ }^{a} \mathrm{~L}$ concordou que as informações veiculadas pelo Whatsapp deveriam se restringir a transferência de dados como: imagens, vídeos, textos e links informativos sobre o conteúdo curricular para facilitar e complementar as atividades, mas que deveriam ser socializados de outra maneira entre aqueles que não tinham smartphones. Ela percebeu que pelo menos dois alunos de cada equipe estavam inseridos no grupo, isso lhe tranquilizou, porque repassavam as informações aos demais. Além disso, optaram em criar um blog para que todos tivessem acesso. 
V Congresso Brasileiro de Informática na Educação (CBIE 2016)

Anais do XXVII Simpósio Brasileiro de Informática na Educação (SBIE 2016)

Para a Prof ${ }^{a}$.L, o celular deve ser usado com muita responsabilidade no contexto escolar, já que se trata de um dispositivo pessoal com diversas configurações. Kukulska-Hulme (2010) destaca que essa tecnologia pode representar uma revolução na educação, pois oferece ao estudante oportunidade de aprender em movimento, tornando o processo de aprendizagem mais atraente, interessante e motivador.

Apesar da Lei $14.146^{1}$ proibir seu uso nas escolas cearenses, a professora tinha um objetivo pedagógico muito claro para seu uso que foi contagiado pelos alunos, disse ela: "Eu quero que os alunos entendam que podemos usar o celular na educação, desde que tenha um sentido educativo por trás disso" (Entrevista: 29/09/2015). Ademais, observamos que o Restaura (nome da cidade) foi também um espaço de organização e de negociações de ideias, retratadas a seguir:

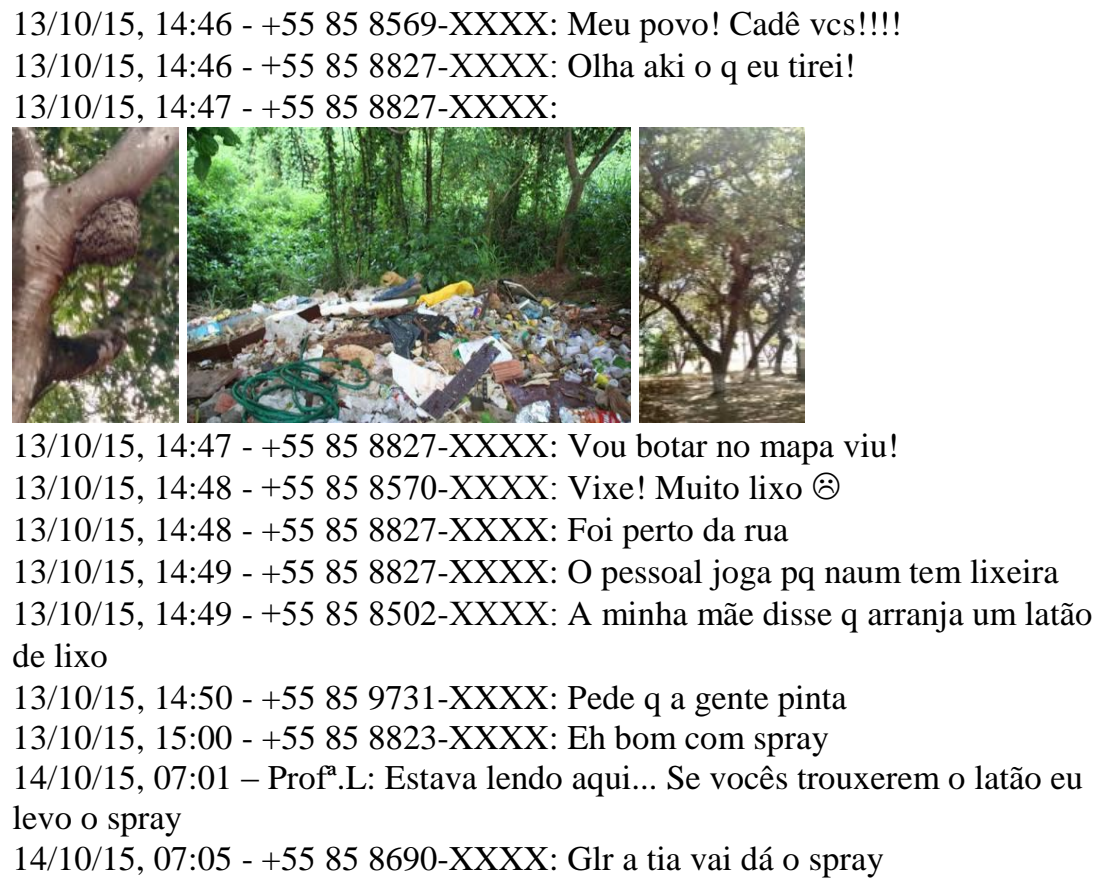

A lei que proíbe o uso de celulares na escola está baseada na ideia de que o professor ministra a aula e os alunos devem assisti-la sem nenhuma interferência ou distração pessoal que perca o foco nos estudos. Nesse contexto, quando não se tem, de forma clara, um objetivo pedagógico para utilizar os celulares ou qualquer outra tecnologia na aula, faz sentido coibi-lo. Entretanto, a Prof ${ }^{a}$ L adota uma perspectiva completamente diferente, uma vez que o smartphone está sendo efetivamente usado como ferramenta educativa, a partir de práticas pedagógicas em que docente e discentes dialogam e trocam informações visando a aprendizagem. Isso foi observado no trecho a seguir:

06/11/15, 09:10 - +55 85 9874-XXXX: Alguém on?

06/11/15, 09:12 - +55 85 8836-XXXX: Tô fazendo a tarefa q a tia (Prof. L) mandou

06/11/15, 09:12 - +55 85 9874-XXXX: Eu tb tu sabe dizer se a samambaia eh uma angiosperma?

\footnotetext{
${ }^{1}$ A Lei $n^{\circ}$ 14.146, de 25.06 .08 (D.O. de 30.06.08), dispõe sobre a proibição do uso de equipamentos de comunicação, eletrônicos e outros aparelhos similares, nos estabelecimentos de ensino do Estado do Ceará, durante o horário das aulas.
} 
V Congresso Brasileiro de Informática na Educação (CBIE 2016)

Anais do XXVII Simpósio Brasileiro de Informática na Educação (SBIE 2016)

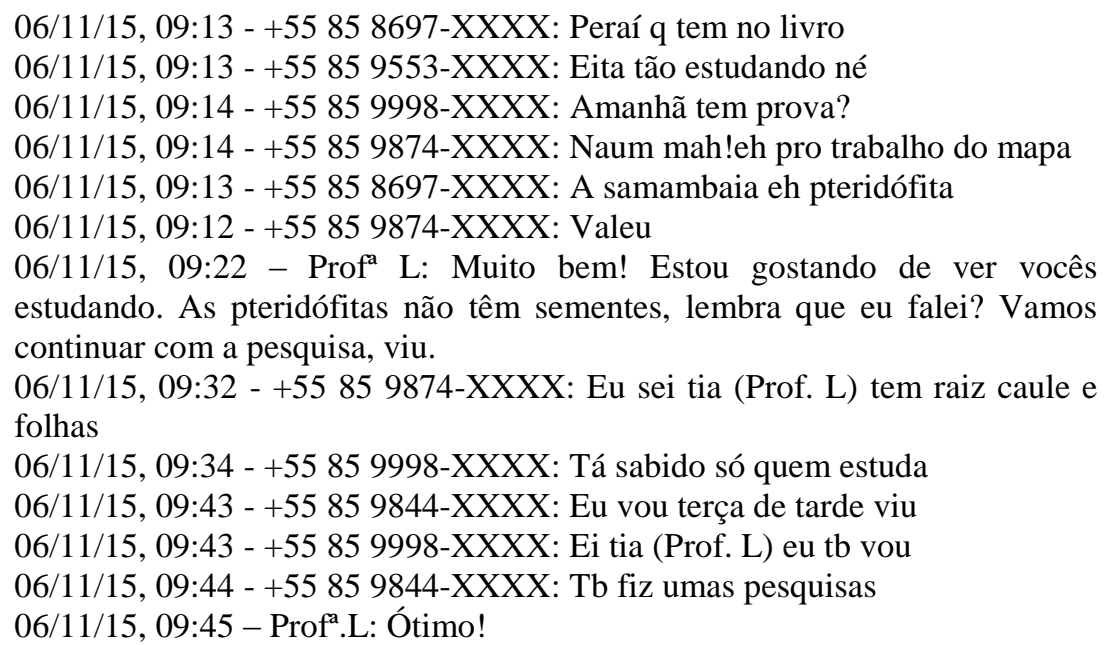

Este fragmento faz menção a aprendizagem em diferentes contextos. A conversa ocorre em um domingo pela manhã de maneira não-formal e iniciada pelo Aluno 9874. Interessante a forma como ele chama os demais do grupo, diz ele: "Alguém on?". Os que estão "ligados" ou conectados participaram da conversa. Inicialmente, percebemos a necessidade de tirar uma dúvida sobre um conteúdo para a realização de uma tarefa, depois outros entram, ajudam ou interpelam com outros assuntos. A Prof ${ }^{a} \mathrm{~L}$ aproveita $\mathrm{o}$ momento para sanar a dúvida dos alunos e reforçar a necessidade do estudo e da pesquisa.

Assim, este serviço de mensagens provocou a reflexão de que as tecnologias desempenham diversos papéis na escola, no entanto, é papel do professor conhecer suas diferentes aplicações, explorando-as para atingir um determinado objetivo educativo (ALMEIDA; VALENTE, 2011). Neste caso, o Whatsapp, muitas vezes utilizado de maneira não-formal na família ou entre amigos, facilitou a troca de informações entre alunos e professora em situações de ensino e aprendizagem.

O uso do celular na sala de aula estava proibido na Escola, mas a direção permitiu a sua utilização após solicitação da Prof ${ }^{\mathrm{a}}$.L, visto que apresentou estratégias para a sua inclusão em sua prática docente. É preciso estar sensível aos avanços técnicos e perceber como essa tecnologia pode ser produtiva em contexto pedagógico.

Liu et al. (2014) destaca que a conectividade pode promover diferentes redes de aprendizagem, porque ela deixa de ser uma atividade interna, individualista para uma atividade externa e colaborativa. $O$ autor reforça que a conectividade pode trazer benefícios na era digital. Entretanto, o sistema educativo tem demorado a reconhecê-la.

Observamos que o "Restaura (nome da cidade)" ampliou a comunicação e compartilhamento entre pares. Conforme Park (2011), as características das tecnologias móveis associadas à conectividade podem ajudar o professor a ampliar os espaços de ensino, a participação em redes de aprendizagem e o trabalho colaborativo. Estes elementos remetem ao pensamento de Vygotsky, pois compreende que as funções psicológicas se fundamentam nas relações entre o indivíduo e o mundo, mediadas pela cultura, ou seja, o indivíduo reage aos estímulos a partir de materiais, conceitos que foram constituídos socialmente.

Além do Whatsapp, a Prof ${ }^{a}$ L disponibilizou um formulário eletrônico para o monitoramento online do bosque (locus do projeto), cuja ideia surgiu a partir de um 
V Congresso Brasileiro de Informática na Educação (CBIE 2016)

Anais do XXVII Simpósio Brasileiro de Informática na Educação (SBIE 2016)

vídeo sugerido por um aluno que tratava sobre um aplicativo para registro de ocorrência de lixo nos bairros. A professora gostou da ideia e pediu ajuda à pesquisadora para pôr em prática. Para esse monitoramento acontecer, foi necessário dividir o bosque em nove partes. A Prof ${ }^{a} \mathrm{~L}$ pediu aos alunos que identificassem cada uma com placas, na tentativa de facilitar o registro dos dados, bem como beneficiar a participação de toda a turma. Percebemos que alguns alunos possuíam conexão de Internet particular em seus smartphones e optavam por responder o monitoramento online do bosque em seu próprio dispositivo do que no tablet da escola (Diário de campo: 10/11/2015).

Após quatro semanas acompanhando o bosque e registrando dados no formulário eletrônico, a Prof ${ }^{a}$.L mostrou na sala de aula, com ajuda da pesquisadora, as respostas sobre o monitoramento online. Afinal eles precisavam analisar os dados gerados com o objetivo de identificar problemas relacionados ao crescimento saudável das plantas e pensar estratégias para solucioná-los.

Diante dos dados apresentados na planilha projetada na lousa, com o intuito de gerar um debate entre os estudantes, a $\operatorname{Prof}^{a} \mathrm{~L}$ fez uma série de perguntas: Como estavam as plantas nas duas primeiras semanas de monitoramento? $\mathrm{O}$ que aconteceu nas duas últimas semanas? A gente teve mais situações onde o solo estava úmido ou seco? Os insetos começaram a aparecer a partir de qual dia? Quais eram os insetos que mais apareciam? (Diário de campo: 24/11/2015).

À medida que os alunos respondiam, a professora pedia para um aluno colorir os itens. Cada semana foi representada de uma cor diferente, assim como para solo úmido a cor azul, para seco a cor marrom, para as formigas a cor roxa (FIGURA 1).

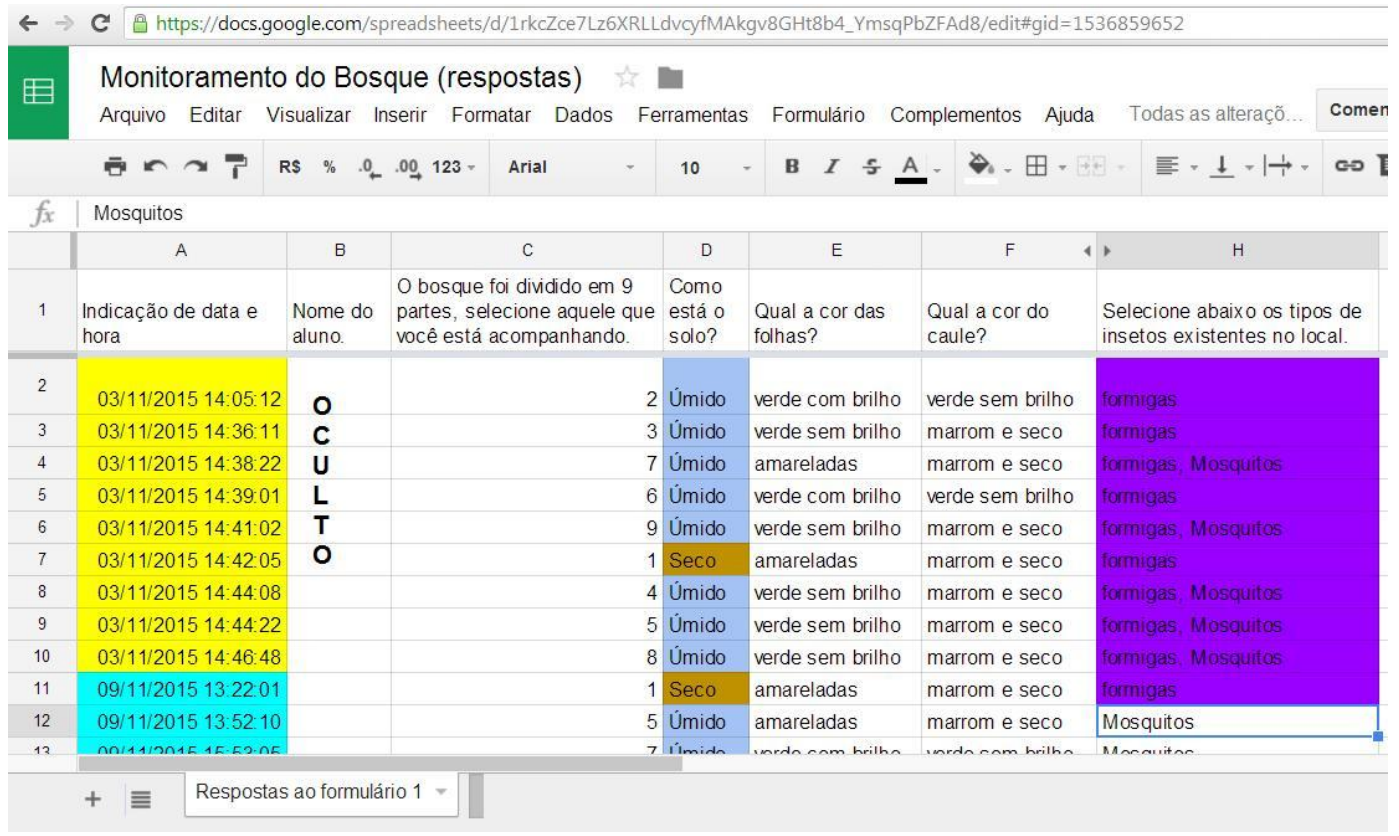

Figura 1. Planilha com as repostas do monitoramento online

A discussão ficou conflituosa quando um grupo observou que o solo ficou seco a partir do dia 16 de novembro, pois acusava outros de não terem regado as plantas como deveriam. A Prof ${ }^{a}$ L tentava acalmar os ânimos dizendo que ninguém estava ali para julgar os colegas e que o momento era de avaliar as condições do bosque, foi, então, que um grupo se defendeu alegando falta d'água no bairro. Outro informou que a mangueira 
V Congresso Brasileiro de Informática na Educação (CBIE 2016)

Anais do XXVII Simpósio Brasileiro de Informática na Educação (SBIE 2016)

da Escola estava quebrada e que não podia regar a área. Talvez se a professora tivesse ocultado a coluna dos nomes dos alunos, esse conflito não tivesse acontecido, por outro lado eles não teriam cogitado a falta d'água e equipamento adequado para irrigação do ambiente como problema.

Em seguida, a Prof ${ }^{a}$ L perguntou aos alunos se eles tinham identificado outro problema. Um aluno reconheceu que boa parte das respostas mostrava a representação de formigas na região. Os estudantes informaram que a maioria das mudas que tinham sido plantadas por eles estava com as folhas roídas, cheias de buraquinhos. Desta forma, a turma se organizou em trios, usou o site de busca Google para selecionar algumas soluções de adubo, pesticidas caseiros para repelir as formigas e anotou no caderno os ingredientes. Então, a $\operatorname{Prof}^{a} \mathrm{~L}$ pediu que eles não deixassem de regar as plantas e combinou um encontro no contraturno de aula para produzir as receitas caseiras e usálas no bosque (Diário de campo: 24/11/2015).

Em relação à avaliação dos alunos, a professora tomou como base 5 (cinco) critérios que, após delegar as ações do projeto aos grupos, foram apresentados à turma, a fim de deixá-la ciente de como as notas seriam calculadas. Assim, cada item valia até dois pontos, os critérios foram: participação, integração com os demais alunos, criatividade na produção da atividade, apresentação oral e criação de perguntas relacionadas aos temas dos outros grupos.

Essa atividade permitiu compartilhar e discutir nas aulas os dados encontrados no campo, como também em contextos não-formais onde os alunos não estavam na escola e muito menos em seus horários de aula. Segundo Almeida e Valente (2014) os espaços não-formais oferecem a aprendizagem fora de um ambiente clássico e de um currículo formal, ela pode acontecer a todo o momento e é influenciada pelo ambiente e por situações particulares vividas pelo indivíduo.

Para Sharples et al. (2010) usar dispositivos móveis para explorar o campo de investigação, receber e compartilhar informações com os colegas e depois voltar à escola para discutir e desenvolver suas interpretações com a turma, tem mais sentido pedagógico pelo fato dessas tecnologias permitirem a relação entre as experiências do mundo real com os assuntos estudados de forma dinâmica.

Para Liu et al. (2014), a mobilidade e o diálogo podem ser facilitados pelos dispositivos móveis durante a aprendizagem móvel, pois são baseados na estreita relação entre os membros de um grupo a partir da interação, conversação e tomada de decisão, incluindo o movimento físico que pode ser difícil no trabalho com computadores fixos. Essa premissa é reforçada na fala da Prof ${ }^{a} . L$ que define a sua concepção sobre tal paradigma,

\begin{abstract}
Se aprendizagem móvel for pensar atividades que ultrapassem as paredes da sala de aula ou os muros da escola, acho que os alunos aproveitaram bastante essa mobilidade e aprenderam muito com ela, porque eles estavam tão envolvidos que traziam para a sala de aula coisas que eles viam nos arredores da escola, na vizinhança, nas praças da cidade onde moram. O que eu vejo é que não ficou só na sala, eles estavam relacionando tudo, até fora da escola (Entrevista: 15/11/2015).
\end{abstract}

Diante dessa discussão, entende-se que a mobilidade pode acontecer sem acesso à Internet e sem trocas de informações. Já a ubiquidade está ligada a computação móvel em que a conexão é sustentada por um dispositivo, independente do movimento do 
V Congresso Brasileiro de Informática na Educação (CBIE 2016)

Anais do XXVII Simpósio Brasileiro de Informática na Educação (SBIE 2016)

individuo. Citamos como exemplo, os smartphones usados por alguns alunos para monitorar as plantas do bosque a partir de um formulário eletrônico ou planilha do Google Drive, cujo link estava disponível no blog da Prof ${ }^{a}$ L que poderia ser acessado em qualquer tempo e espaço, como também a possibilidade de aprofundar a pesquisa sobre as plantas, armazenar e compartilhar informações.

Assim, a aprendizagem móvel estimulou a interação dos alunos face à mediação docente, bem como foi um instrumento de produção colaborativa durante o projeto. Essa abordagem assume que o acompanhamento contínuo é um elemento importante para verificar o processo de mudança dos alunos na realização de atividades menos complexas para as mais complexas (TRAXLER, 2010).

Com uma variedade de recursos disponíveis na Internet, a aprendizagem móvel oferece opções que ampliam o processo de ensino e aprendizagem, tanto no acesso quanto na produção de conteúdos a qualquer hora e lugar, oportunizando aprendizagem formal e não-formal dentro ou fora da sala de aula.

\section{Considerações finais}

Este estudo apresenta algumas implicações para o campo da aprendizagem colaborativa móvel no Ensino Fundamental. Os dados gerados do diário de campo e entrevistas puderam constatar que as tecnologias móveis possuem potenciais recursos de ensino e aprendizagem formal e não-formal tanto para os professores, como para os estudantes.

Integrar as tecnologias móveis em práticas colaborativas no contexto educativo implica pensar nos benefícios de uma variedade de recursos disponíveis no mercado, bem como na possibilidade de apoiar novas estratégicas pedagógicas. Isso ficou bastante representado no projeto, pois a Prof ${ }^{a} \mathrm{~L}$ atribuiu maior responsabilidade aos alunos na construção da sua aprendizagem, investindo no protagonismo juvenil, ensinando-os a lidar com as transformações do meio ambiente, com as frustrações, com a criticidade dos fatos, mas também com o trabalho colaborativo, com as habilidades e competências de cada um e com a flexibilidade, criatividade e dinamismo ao usar os dispositivos móveis nas aulas.

Essa prática de ensino não se concentrou na tecnologia em si, mas no seu valor para desenvolver práticas colaborativas na e além da sala de aula. O mais importante não foi o tablet e nem o smartphone, mas a forma como a Prof ${ }^{a}$.L conduziu, mediou, orquestrou todo o processo com seus alunos.

\section{Referências}

Almeida, M. E. B. e Valente, J. A. Tecnologias e currículo: trajetórias convergentes ou divergentes. São Paulo: Paulus, p. 6-8, 2011.

Almeida, M. E. B. de; Valente, J. A. Currículo e Contextos de Aprendizagem: integração entre o formal e o não-formal por meio de tecnologias digitais. Revista Científica e-Curriculum, v. 12, n. 2, p. 1162-1188, 2014. Disponível em: http://revistas.pucsp.br/index.php/curriculum/article/view/20355 Acesso em: 11 ago. 2016.

Kukulska-Hulme, A. Mobile learning as a catalyst for change. Open Learning, v. 25, n.
3 ,
p.
181-185,
2010.
Disponível
em: 
V Congresso Brasileiro de Informática na Educação (CBIE 2016)

Anais do XXVII Simpósio Brasileiro de Informática na Educação (SBIE 2016)

http://www.jstor.org/stable/jeductechsoci.13.4.4?seq=1\#page_scan_tab_contents Acesso em: 23 mai. 2016.

Liu, M.; Navarrete, C. C.; Wivagg, J. Potentials of Mobile Technology for K-12 Education: An Investigation of iPod touch Use for English Language Learners in the United States. Educational Technology \& Society, 2014, p. 115-12.

Mehdipour, Y.; Zerehkafi, H. Mobile Learning for Education: Benefits and Challenges. In: International Journal of Computational Engineering Research, v. 3, n. 6, p. 93 101, 2013. Disponível em http://citeseerx.ist.psu.edu/viewdoc/download?doi=10.1.1.412.4457\&rep=rep1\&type $=$ pdf\#page $=251$. Acesso em 23 de maio de 2016.

Nascimento, K. A. S. e Castro Filho, J. A. Aprendizagem móvel e suas tecnologias: uma revisão sistemática da literatura. In: Anais do Workshop de Tecnologia Móveis na Educação do Congresso Brasileiro de Informática na Educação-CBIE, 2015.

Park, Y. A. pedagogical framework for mobile learning: Categorizing educational applications of mobile technologies into four types. The International Review of Research in Open and Distributed Learning, v. 12, n. 2, p. 78-102, 2011. Disponível em http://www.irrodl.org/index.php/irrodl/article/view/791 Acesso em 23 de maio de 2016.

Roschelle, J.; Rafanan, K.; Estrella, G.; Nussbaum, M.; Claro, S. From handheld collaborative tool to effective classroom module: Embedding CSCL in a broader design framework. Computers \& Education, v. 55, n. 3, p. 1018-1026, 2010. Disponível em http://www.sciencedirect.com/science/article/pii/S0360131510001193. Acesso em 23 de maio de 2016.

Sharples, Mike; Taylor, Josie; Vavoula, Giasemi. A theory of learning for the mobile age. In: Medienbildung in neuen Kulturräumen. VS Verlag für Sozialwissenschaften, 2010. p. 87-99.

Silva, M. A., Barbosa, J. R., Castro-Filho, J. A. de. Aprendendo e Ensinando Colaborativamente com o Suporte do Laptop Educacional. In: Anais do II Worshop Um Computador por Aluno do Congresso Brasileiro de Informática na Educação CBIE, 2013. $\quad$ v. $1 . \quad$ Disponível em http://www.brie.org/pub/index.php/wcbie/article/view/2726/2380. Acesso em: 23 de maio de 2016.

Thiollent, M. Metodologia da Pesquisa-Ação. São Paulo: Cortez, 1985.

Traxler, J. Students and mobile devices. Research in Learning Technology, v. 18, n. 2, 2010.

Vygotsky, L. S. A formação social da mente: o desenvolvimento dos processos psicológicos superiores. $7^{\mathrm{a}}$ Ed. São Paulo: Martins Fontes, 2007. 